\title{
Communication and the representation of thought: The use of audience-directed expressions in free indirect thought representations ${ }^{1}$
}

\author{
DIANE BLAKEMORE
}

\author{
University of Salford
}

(Received I8 May 2009; revised 4 September 2009)

This paper examines the use of audience-directed or inherently communicative expressions (discourse markers and interjections) in free indirect thought representations in fiction. It argues that the insights of Banfield's (I982) no-narrator approach to free indirect style can be accommodated in a relevance theoretic framework. The result is an account in which the author's act of revealing a character's thoughts communicates a guarantee of optimal relevance - a guarantee which justifies the effort which the reader invests in deriving meta-representations of those thoughts from the evidence which the author provides. However, the reward for this effort is a meta-representation of a character's thoughts which is unmediated by the thoughts of the author who is responsible for producing the text. Using examples from fiction, I show that within this framework, the use of procedurally encoded discourse markers and interjections contribute to this sense of immediacy by imposing constraints on interpretation which leave the reader with the responsibility for deriving his own interpretations of a character's thoughts and thought processes.

\section{EXPRESSIVITY MARKERS IN FREE INDIRECT THOUGHT}

Within relevance theory it has been argued that the meanings of a subset of the expressions labelled 'discourse markers', including standard cases of Gricean conventional implicature (however, therefore, moreover), should be analysed in terms of the way they constrain or direct pragmatic inference rather than the way they contribute to the conceptual content of the utterances that contain them (Blakemore 1987, 2002). This distinction between procedural and conceptual meaning reflects the representational/ computational approach to cognition which underpins Sperber \& Wilson's (I995) relevance theoretic approach to utterance interpretation. However, it is also justified in terms of the pragmatic principle which, according to relevance theory, is essential for the explanation of how human communication

[I] I am extremely grateful to Nigel Fabb and two anonymous $J L$ referees for comments on earlier versions of this paper. Obviously, they are not to be held responsible for any of the arguments it contains. 
is achieved. According to this principle, every act of ostensive communication communicates a guarantee of optimal relevance so that it may be assumed that the communicator has aimed to achieve the highest level of relevance he is capable of within the parameters of his abilities and interests. Since the degree of relevance increases with the number of cognitive effects derived and decreases with the amount of processing effort required for their derivation, the use of an expression which encodes a procedure for identifying the intended cognitive effects would be advantageous from a processing point of view: it provides a means of ensuring the identification of the intended cognitive effects for a minimum cost in effort. ${ }^{2}$

On this approach, expressions which encode procedures rather than concepts are intrinsically linked to communication: their function is to reduce the effort which the hearer must invest in recovering the intended interpretation of an utterance. In real life, communicators produce public representations (utterances) of their private thoughts, and hearers are intended to use the linguistic properties of these utterances and contextual assumptions in the derivation of interpretations of those thoughts. In fiction, authors may REPRESENT fictional acts of communication in which fictional speakers are represented as producing utterances which readers are meant to assume are interpreted by fictional hearers. Clearly, there is a limit to the extent to which these representations of fictional acts of communication resemble actual acts of communication. An author may attempt an orthographic indication of a character's accent (see Fludernik 1993: 259-260), or orthographic representations of features such as emphatic stress. But in general the representation is a less than verbatim record of the utterance which the character is supposed to have made. ${ }^{3}$ Nevertheless, according to the relevance theoretic framework of this paper, an author who is representing a character engaged in the act of communication must be assumed to be representing someone who is aiming at optimal relevance. This means that it is not particularly surprising that fictional communicators are represented as using expressions which encode procedures, or, in other words, expressions which are inherently communicative in the sense outlined above. The only difference is that in such cases the expression is linked to a represented act of communication rather than an actual one.

However, in free indirect thought (FIT) these 'intrinsically communicative' or audience-directed devices are used by writers in their representations of thoughts which must be attributed to characters who are not engaged in an act of communication at all. For example, in (I) well must be attributed to

[2] For further discussion see Blakemore 2002, Wilson \& Sperber 1993.

[3] Fludernik (1993) argues that representations of utterances can only be representations of utterance types and that all speech and thought representation relies on a mechanism of schematization which is independent of actual thought processes. 
Mansfield's character Linda Burnell, who is represented as simply thinking (underlining in this example and the ones which follow is my own):

(I) And what made it doubly hard to bear was, she did not love her children. ... Even if she had the strength she would never had nursed and played with the little girls. No, it was as though a cold breath had chilled her through and through on each of those awful journeys; she had no warmth left to give them. As to the boy - well, thank heaven, mother had taken him.

(Katherine Mansfield, 'At the Bay', Collected Stories, p. 223)

Similarly, in (2), anyway must be attributed to Grace's character, Rua, who is engaged not in the act of communication, but in the act of thought:

(2) Not long after sunrise he'd thrown his line out and spent about an hour before catching two fish, then he'd scaled and cleaned them, washed up, taken his time coming back. Probably getting on for eight o'clock. Anyway, it was all his own doing, getting her to come here. Why had he?

(Patricia Grace, Dogside Story, p. 75)

Discourse markers are amongst a whole range of expressions and structures found in FIT which are said to function as markers of expressivity or subjectivity (Banfield 1982, Fludernik 1993). These include a heterogeneous class of items, usually called interjections, some of which are considered to be marginal to language. Examples include $a h$ in (3), oh in (4), good heavens in (5) and Linda Burnell's no in (I):

(3) Linda was astonished at the confidence of this little creature ... Ah, no, be sincere. That was not what she felt; it was something far different, it was something so new, so ...

(Katherine Mansfield, 'At the Bay', Collected Stories, p. 223)

(4) Oh, how marvellous to have a brother! In her excitement Leila felt that if there had been time, if it hadn't been impossible, she couldn't have helped crying because she was an only child and no brother had ever said 'Twig?' to her; no sister would ever say, as Meg said to Jose at that moment, 'I've never known your hair go up more successfully than it has tonight'.

(Katherine Mansfield, 'Her First Ball', Collected Stories, p. 337)

(5) And once too in his studio, where the Consul was so obviously not going to arrive, M. Laruelle had shown her some stills of his old French films, one of which it turned out - good heavens! - she'd seen in New York.

(Malcolm Lowry, Under the Volcano, p. 267)

Since these expressions signify feelings or states of minds rather than concepts which can be explicated, they cannot be straightforwardly accommodated in 
a translational semantics for natural language (cf. Kaplan 1997; Wharton 2003a, b). Thus Kaplan (1997) argues that, in contrast with words such as fortnight and feral, these expressions encode information about the contexts in which they are appropriate, or, in other words, that they require a SEMANTICS OF USE rather than a SEMANTICS OF MEANINGS. And within a relevance theoretic framework, Wharton $(2003 \mathrm{a}, \mathrm{b})$ has argued that while interjections such as $a h$ and $o h$ may not be properly linguistic, they nevertheless have a coded element which is procedural in the sense that they are used by speakers in order to encourage the hearer to construct conceptual representations of the emotions and attitudes they wish to communicate. ${ }^{4}$ However, the interjections in (3)-(5) above are all attributable to characters who are engaged not in acts of communication but in acts of thought. While one can see why a communicator might use an expression which encourages a hearer/reader to construct a meta-representation of the emotions he is experiencing, it seems difficult to see how such an expression could play a role in thought.

The question, then, is how can we justify the use of expressions which, according to the relevance theoretic approach outlined above, are not constituents of thoughts in representations of the thoughts of characters who are engaged in private thought rather than communication?

There is no question that this must be justified. The authors cited above cannot be accused of doing something which is somehow illegitimate. As we shall see in this paper, these expressions play an important role in creating an impression of being able to gain entry to a character's mind, or of being able to witness him/her as s/he is actually having the thoughts in much the same way that we are able to witness a speaker as he constructs utterances as public representations of his own thoughts. This effect is often encapsulated in the description of FIT as 'inner speech' (cf. Chatman 1978, Ehrlich 1990). However, as I have just argued, this is not 'speech' in the sense of an act of communication intended for a hearer. It is not represented speech, but represented thought.

Here we have the key to the answer to the question I have just posed. The point is that these are public REPRESENTATIONS of thoughts, and these cannot be confused with the private thoughts they represent. The fact that the use of expressions such as well, anyway, ah and oh gives us access to the minds of the characters whose thoughts are being represented does not mean that these expressions are actually constituents of the thoughts being represented.

[4] Potts (2007) has applied this sort of approach to expressive APs and NP epithets. His argument is that these expressions should be treated as devices for situating the utterances which contain them within the discourse, or as operators which change the context in specific ways. Since these expressions are also a characteristic feature of free indirect thought representations, it would seem that my discussion of the role of interjections in FIT may be extended to include expressive APs (e.g. bloody, damn) and NP epithets (the bastard). 
It might seem that the point I am making here is no different from the point that utterances made by communicating speakers should not be confused with the thoughts they represent, and hence that the presence of expressions such as well, anyway, ah and oh in FIT deserves no more explanation than their presence in any utterance which communicates the speaker's thoughts. However, this paper assumes that there is a difference between the two cases. An utterance made in the course of real-life (or, indeed, simulated) communication is evidence of the communicator's intention that the audience should derive an interpretation which is a representation of that communicator's thoughts. The speaker is communicating HIs thoughts. As we shall see, he may entertain a thought as a representation of another person's thoughts, in which case the utterance can be said to be used attributively. But it is still the SPEAKER who is entertaining this thought as a representation of another thought.

A FIT representation, on the other hand, is simply intended as a representation of someone else's thoughts. In producing a FIT representation, the author cannot be understood to be communicating his thoughts, but must simply be taken to be representing thoughts which are being entertained by another. In other words, a FIT representation is unmediated by the thoughts of a communicating speaker.

In this paper, I argue that the use of discourse markers and expressive interjections in FIT representations must be explained in terms of an approach to FIT which is able to capture this difference. In section 2, I outline the relevance theoretic approach to attributively used utterances and argue that it does not capture the difference between communicated thought and represented thought just outlined. In section 3, I address the question of whether the use of expressive devices in FIT can serve as a means of distinguishing FIT representations from indirect thought representations. In section 4, I argue for a relevance theoretic account of FIT representations which departs from the one suggested by Wilson (2006) in terms of tacit attributive use. And in section 5, I show how this approach serves as the basis for the explanation of the use of discourse markers, expletives and interjections in FIT representations. Section 6 concludes the paper.

\section{RELEVANCE AND META-REPRESENTATION}

Within relevance theory, Wilson $(1995,2000)$ have shown that the ability to form meta-representations or representations of representations is fundamental to the explanation of linguistic communication. In the first place, since an utterance is a public representation which has a propositional form, it can be used to represent another representation which has a propositional form - or, in other words, a thought. However, utterances do not communicate thoughts by duplicating them. All we can say is that utterances INTERPRET the thoughts they are used to communicate (Sperber \& Wilson 
I995: 230). An utterance is an interpretation of a thought to the extent that its propositional form resembles the communicator's thought, or, in other words, to the extent that it shares logical and contextual implications with that thought. The more implications they share, the closer the resemblance, and identity is simply a special case of resemblance, in which the propositional form of the utterance shares all the implications of the thought in every context.

The hearer's task in interpreting this utterance is to use the utterance as a means of deriving a representation of the speaker's thought $-\mathrm{a}$ thought about a thought. However, once again it is not assumed that the representation derived by the hearer duplicates that thought. The hearer must use pragmatic inference to bridge the gap between the linguistically encoded meaning of the utterance and its interpretation. Since the linguistic evidence provided by the utterance may give the hearer varying degrees of responsibility for deriving an interpretation which satisfies his expectations of relevance, it is possible that he will use the utterance as a means for deriving assumptions which are not identical with ones envisaged by the speaker. That is, the thoughts derived by the hearer will simply be assumed to be an interpretation of the speaker's thoughts, and communication will succeed to the extent that it results in the enlargement of the mutual cognitive environment of speaker and hearer. ${ }^{5}$

However, as Sperber \& Wilson show, the thought represented by an utterance may itself be entertained by the speaker as a representation of another (attributed) thought. Consider the summary of a speech, or the minutes of a meeting, or a report made by a speaker of another person's utterance or thought attributed made by another. Once again the intention is not necessarily to replicate that utterance or thought. Even so-called direct representations do not necessarily reproduce the original exactly. The following was heard in a reading of a story for children (BBC Radio 7):

(6) 'Who said you could put your bottom on my chair', he said - except he didn't use the word bottom.

Similar examples are given by Wilson (2000). In the narrratology literature, the idea that direct discourse is a verbatim representation of the original has also been exposed as a myth (see Sternberg I982, Fludernik 1993). Thus Fludernik (I993: 409-4IO) cites both non-literary (oral) and literary examples

[5] Sperber \& Wilson (I995) define the COGNITIVE ENVIRONMENT of an individual as the set of assumptions which are MANIFEST to an individual at a given time, where MANIFESTNESS is defined in terms of the degree to which an individual is capable of representing an assumption and holding it as true or probably true at a given time. A MUTUAL COGNITIVE ENVIRONMENT is a cognitive environment which is shared by a number of individuals and in which it is manifest to those individuals that they share it with each other. 
of cases in which a narrator attributes a thought or statement to characters who have not uttered a word.

(7) And I just felt like, 'This is where I belong'. (from Tannen I989: I52)

(8) An approving murmur arose from the heads of tribes; as saying, 'There you have him! Hold him!'

(Charles Dickens, Our Mutual Friend I, xi, p. I87)

As Wilson (2000) points out, languages have a variety of devices available to speakers for indicating attributive intentions - for example, parenthetical clauses such as 'he thought' or 'he said', hearsay sentence adverbials such as 'allegedly' or 'according to Pam', hearsay particles, prepositions, and modals. ${ }^{6}$ However, in many cases, the speaker's intentions are not indicated by the form of his utterance and the hearer will have to use pragmatic inference to work out that an utterance is intended as a representation of an attributed thought. For example, in (9) below, the speaker's use of the sentence adverbial according to Pam indicates that the thought which is interpreted by the segment in (b) is being entertained as a representation of Pam's thought, and hence that the hearer should recover the higher-level explicature in (II). However, in (IO), the attribution is tacit and the hearer is intended to infer that the utterance is being used attributively on the basis of the context and the Principle of Relevance:

(9) (a) I thought it was really nice. (b) But according to Pam, I looked ridiculous.

(Io) [The speaker, who has been trying on a dress in a shop, emerges from the changing cubicle and looks questioningly at her friend who prepares herself to say something tactful]

Friend: Well, ...

Speaker: I look ridiculous.

(II) Pam thinks I look ridiculous.

According to Wilson (2006), free indirect speech and thought can be treated along the same lines as (IO), as a tacitly attributive uses of language. Thus she argues that the second segment of (I2) will be misunderstood if it is not understood that the speaker is thinking about what the students are thinking rather thinking directly about a particular state of affairs.

(I2) (a) The students were thoughtful. (b) If they didn't act now, it would be too late.

(from Wilson 2006: I730, ex. (I2))

[6] For further discussion of the various devices used to indicate attributive intentions, see Blass (I989, I990), Ifantidou-Trouki (I993), Wilson \& Sperber (I993). 
In fact, as Banfield (1982: 76-88), Ehrlich (1982: 76-88) and Fludernik (1993: I65, 240-24I, 285-297) have pointed out, authors who provide FIT representations may use parentheticals to explicitly indicate the source of the represented thought and its mode of representation. The example in (I3) is cited by Ehrlich (I990), while (I4)-(I6) are cited in Blakemore (2008): ${ }^{7}$

(13) Her shoes were excellent, he observed.

(Virginia Woolf, To the Lighthouse, p. 22)

(I4) Human relations were all like that, she thought, and the worst (if it had not been for Mr Bankes) were between men and women.

(Virginia Woolf, To the Lighthouse, p. 107)

(I5) Yvonne knew where she was now, but the two alternatives, the two paths, stretched out before her on either side like the arms - the oddly dislocated thought struck her - of a man being crucified.

(Malcolm Lowry, Under the Volcano, p. 319)

(I6) So the 'other' had come again. And now gone, he thought: but no, not quite, for there was still something there, in some way connected with it, or here, at his elbow, or behind his back, in front of him now ...

(Malcolm Lowry, Under the Volcano, p. 96)

However, whether or not the source of the represented thought is indicated by a parenthetical, it seems that FIT representations must be distinguished from utterances such as (9) or (IO). Notice that although the speaker of (IO) will be understood to be using his utterance attributively, the attributed thought it is being used to represent is nevertheless being viewed from the speaker's perspective. As Reinhart (1983) and Ehrlich (1990) have pointed out, whereas in free indirect thought representations it has to be assumed that the person whose thought is being represented actually had that thought (or one something like it), this is not the case in indirect thought representations. Thus in (IO), the speaker may have simply inferred that Pam had the thought that he looked ridiculous on the basis of his observations of Pam's behaviour.

Moreover, whereas in tacit indirect thought the speaker may use an expressive to indicate that the attributed thought is being seen from his own point of view, in free indirect thought, expressives must be attributed to the character whose thoughts are represented. For example, while Pam can be

[7] As Reinhart (I983) has shown, sentences containing parentheticals which indicate the source of a free indirect style thought or speech representation and its mode of representation are characterized by backward pronominalization and tense agreement. In contrast, in sentences containing parentheticals which indicate the source of a thought/speech representation from the speaker's point of view, forward pronominalization is obligatory and the tense of the main clause is determined in relation to real time. For further discussion, see Ehrlich (I990). 
attributed with the thought that the speaker looks ridiculous in (I7), the expletive can be attributed to the speaker:

(I7) [The speaker emerges from a changing cubicle in a clothes shop and looks questioningly at Pam who prepares herself to say something tactful]

Pam: Well, ...

Speaker: Oh God I look ridiculous.

Similarly, in (I8), while the speaker will be understood to be attributing the thought that she looks ridiculous to someone else (Pam), she must be understood as the source of the discourse marker so:

(I8) [The speaker emerges from a changing cubicle in a clothes shop and sees the look of shocked disapproval on her friend's face]

So I look ridiculous. Is there anything in this shop you approve of?

In contrast, in the constructed FIT examples in (I9) and (20), My God and so must be attributed to the person whose thoughts are being represented, and we are intended to view these thoughts from the perspective of that person:

(I9) My God, how ridiculous he looked.

(20) So he had come.

The fact that that in tacitly attributed utterances, expletives and discourse markers can be attributed to the speaker who is attributing the represented thought rather than to the person whose thought is being represented suggests that we are intended to understand that this thought is being viewed from the perspective of the speaker rather than the source of the attributed thought. However, the fact that the expressives in (I9) and (20) must be attributed to the character whose thought is being represented suggests that we are intended to view this thought from the perspective of this person rather than the speaker who is responsible for representing it.

\section{PROCEDURAL MEANING in INDIRECT THOUGHT REPORTS}

The presence of expressive devices in free indirect thought representations is often contrasted with their absence in indirect thought representations. Thus for example, while good heavens is acceptable in the FIT passage in (5), it cannot be interpreted as falling under the scope of the verb think in $(2 \mathrm{I})$ :

(2I) ?She thought that good heavens she had seen it in New York.

However, it seems that the question of whether these devices can occur in indirect discourse is far from straightforward. Thus both Fludernik (I993) 
and Potts (2007) have shown that expletives and expressive epithets can fall under the scope of certain verbs in indirect speech reports:

(22) Mr Sparkler, growing rash on his late success, observed that Edward had, biggod, a long bout of it, ...

(Charles Dickens, Little Dorrit I, xxiv, p. 762, cited by Fludernik I993: 239; my underlining)

(23) My father screamed that he would never allow me to marry that bastard Webster. However, I would never have gone out with him if I had thought he was a bastard.

(adapted from example due to A. Kratzer, cited by Potts 2007: 7, ex. (I5); my underlining)

Moreover, as Rieber, (I997), Bach (I999) and Potts (2005) have shown, certain discourse markers which have been analysed in procedural terms may fall within the scope of indirect thought reports. (24) is based on an example from Wilson \& Sperber (I993), while (25) is from Potts (2005):

(24) Henry thought that Sue had had holiday and so he should have one too.

(25) Marv thinks that Shaq is huge but [that he is] agile.

If expressives and discourse markers fall within the scope of indirect thought reports, as these examples suggest, then it would seem that there is one less argument from distinguishing free indirect discourse from standard indirect discourse. $^{8}$

Examples such as (22) and (23) might be dismissed as unproblematic since they can be treated as cases of implicit direct quotation (see Hall 2007 for discussion). This, however, is not an option in indirect thought reports, since the subject cannot be understood to have produced an utterance, and it seems that the assumption that ejectives and expressive epithets cannot fall within the scope of indirect thought reports must hold. Notice that in contrast with (23), the speaker's dissociation from the epithet in the second segment of the indirect thought report in (26) is odd:

(26) My father thinks that I shouldn't marry that bastard Webster. ?However, I would never have gone out with him if I had thought he was a bastard.

[8] See Schlenker (2004) and Sharvit (2008) for discussion of the question of whether free indirect discourse is more like direct discourse than indirect discourse from the perspective of formal semantics, and in particular, from the perspective of the interpretation of tense, pronouns, and other indexicals (e.g. here, now, that). See below (section 4) for discussion of Schlenker's solution to the puzzle of free indirect discourse. 
However, this leaves us with the examples in (24) and (25) where, it seems, so and but fall within the scope of the indirect thought report. If, as Bach (1999) has argued, the speaker of these utterances is attributing thought contents, then it would seem that so and but would have to be analysed as contributing to those contents rather than as audience directed devices for constraining interpretation. And indeed, Potts (2005:39) has argued that the fact that but must be regarded as part of the utterance's truth conditional or 'at issue' content explains why the entirety of its content is attributed, not to the speaker, but to the subject of the verb of saying or thinking when it is used in an indirect speech or thought report.

Bach's (1999) solution focuses on utterances containing but, which, he claims, express multiple propositions, all of which are part of its truth conditional content. Thus an utterance such as (27) expresses the propositions in (28):

(27) Shaq is huge but agile.

(28) (a) Shaq is huge.

(b) Shaq is agile.

(c) There is a certain contrast between being huge and agile.

The fact that but (c) does not seem to affect the truth of (27), Bach argues, is explained by saying that it is usually part of common ground and hence not salient in assessments of truth or falsity. However, as Hall (2007) points out, Bach's account does not explain why the proposition that there is a contrast happens to be backgrounded in all cases EXCEPT for speech and thought reports.

In fact, it seems that there are uses of but and so which become unacceptable when they are embedded in indirect thought reports. Consider, for example, a situation in which Jane believes that Henry has gone shopping for food and sees him return empty-handed. In this context, Jane might produce the utterance in (29):

(29) So we've got nothing for dinner.

Alternatively, Henry might anticipate Jane's utterance and produce the indirect thought report in (30):

(30) You think that we've got nothing for dinner.

However, he cannot produce the unacceptable indirect thought report in $(3 \mathrm{I})$ :

(3I) ??You think that so we've got nothing for dinner.

Similar examples can be constructed for but. Thus in a context in which Henry has asked Jane to distribute the handouts for a lecture, Jane's 
utterance in (32) is acceptable, as is Henry's indirect thought report in (33). However, the indirect thought report in (34) is unacceptable:

(32) But there are not going to be enough.

(33) You think that there aren't going to be enough.

(34) ??You think that but there aren't going to be enough.

The point is, of course, that whatever explanation is given for the unacceptability of (3I) or (34) would have to be consistent with the acceptability of (29) or (32).

It seems that this explanation can be found in a procedural analysis of so and but in the indirect thought reports in (24) and (25). As we have seen in section 2, indirect thought reports are reports of what the SPEAKER thinks about the subject's thoughts, and these may include reports of how the subject thinks specific propositions are related in an inference. Given that the relevance of such a report lies in the speaker's interpretation of what the hearer thinks, then it is in the speaker's interests that the hearer is able to identify this interpretation on the basis of the utterance he makes. Since the function of words such as but and so is to make particular inferential routes accessible, one might expect a speaker who wishes to represent a subject as thinking that propositions are related in a particular kind of inference to use these words in order to ensure that the hearer derives the intended interpretation of his utterance for a minimum cost in processing. The interpretation recovered by the hearer on the basis of the meanings of each of these expressions is an interpretation of the speaker's interpretation of the subject's thoughts/inferences. However, this is not to say that the hearer will attribute the speaker with the thought that the subject has a thought which contains constituents corresponding to but or so. The hearer will attribute the speaker with the thought that the subject can be attributed with the thought that the propositions which are included within the scope of the thought report are related in a particular kind of inference. The role of so or but is simply to indicate what kind of inferential relationship this is.

Returning now to (29)-(3I), we can see that the speaker of (29) (Jane) is not expressing a thought about an inferential relationship, but is simply expressing a thought (that they have nothing for dinner) and indicating how it achieves relevance (as a contextual implication from an assumption which is assumed to be mutually manifest). It is, of course, possible for someone (Henry) to attribute him with the thought which she has expressed (as in (30)). However, since so does not contribute to the content of the thought which Jane expresses in (29), but simply constrains the hearer's interpretation of it, it cannot be part of the thought content which Henry is attributing to her in (3I). But nor is it being used to indicate how Jane thinks two propositions are related in an inference. It is not surprising, then, that (3I) is unacceptable. The examples in (32)-(34) can be explained along similar lines. 
4. ThE REPRESENTATION OF THOUght in FICTION: A RELEVANCE THEORETIC RE-ASSESSMENT

In contrast with the indirect thought reports in (3I) and (34), the free indirect thought reports in (35) and (36) are acceptable:

(35) So there would be nothing for dinner, she thought.

(36) But there were not going to be enough, she thought.

This brings us back to the question with which we began, and the main focus of this paper: how do we account for the use of intrinsically communicative devices in the representation of the thoughts of a subject not engaged in the act of communication? In this section, I develop an account of free indirect style which is based on Sperber \& Wilson's relevance theoretic approach to communication, but which incorporates the insights of Banfield (1982), who argues that the interpretation of a free indirect discourse text must be contrasted with the interpretation of communicated discourse since its interpretation does not require the identification of a (speaking) communicator and a hearer, but simply the identification of the point of view (SELF) of the character whose thoughts and utterances are being represented.

It might seem that such an account is impossible. Sperber \& Wilson's theory is a theory of communication: interpretation is constrained by the expectations of relevance which follow from the hearer's recognition that an act of ostensive communication has been performed. Banfield, on the other hand, distinguishes narration and representation in fiction (the EXPRESSIVE dimension of language) from communication (TEXT), where the speaker's very presence guarantees the possibility of $I$ (cf. Banfield 2005: 396).

However, as we have seen, in relevance theory communication is defined in pragmatic terms: the question of whether an act of ostensive communication has been performed is not determined linguistically. Banfield's distinction between communication and the expressive dimension of language is, in contrast, a LINGUISTIC distinction corresponding to the distinction between language whose interpretation depends on the deictic centres SPEAKER and HEARER ( $I$ and you), on the one hand, and language whose interpretation depends on the deictic centre SELF (the point of view of the character whose thoughts are being represented).

It seems that there is a similar distinction underlying Schlenker's (2004) proposals for the analysis of indexicals in free indirect discourse and the historical present. Schlenker distinguishes between the CONTEXT OF UTTERANCE (the point at which a thought is expressed) and CONTEXT OF THOUGHT (the point at which a thought originates ${ }^{9}$ ), arguing that indexicals must be classified according to the context with respect to which they are evaluated. In particular, whereas the interpretation of tenses and pronouns depend on the context of utterance, the interpretation of other indexicals

[9] This seems to correspond to what is called 'point of view' in the narratology literature. 
(e.g. now, here, yesterday, this, that) depends on the context of thought. In ordinary (e.g. face-to-face) communication (Banfield's $I$ speaking to you) these two contexts coincide. However, in free indirect discourse thought they do not, thus creating the impression that another person's thoughts are being articulated through another person's mouth.

Following Banfield and Schlenker, it seems that we could say that as they are used in free indirect discourse, expressives depend for their interpretation on the context of thought rather than the context of utterance. However, as we shall see, not all aspects of the interpretation of a represented thought depend on the context of thought, where this is defined as the point where the thought originates. Many of the conclusions that we draw from such a representation depend on contextual assumptions derived from our interpretation of other character's thoughts, and, in some cases, on the point of view of the author (so-called 'authorial intrusion'). Moreover, as Fludernik (I993) shows, point of view is not always established linguistically. In some cases, it is not possible to identify a reflecting character whose point of view is being represented. ${ }^{10}$ Further, while expressive devices may evoke expressivity, the actual subject of consciousness must be inferred pragmatically on the basis of contextual assumptions made accessible by the text. Finally, as we have seen in section 3, expressives are not restricted to free indirect discourse: they may be embedded within the scope of indirect speech and thought reports. Fludernik concludes that expressive elements must be treated as signals used to 'evoke subjectivity rather than a mere surface structure of underlying actual consciousness or SELF' (I993: 398; emphasis in the original).

My proposal is that the distinction Banfield draws between communication and representation should in fact be drawn in pragmatics. Moreover, in contrast with Banfield, I do not interpret this distinction as a distinction between a non-communicative use of language and a communicative use. Within a relevance theoretic framework, the representation of thought (and speech) in fiction is a variety of ostensive communication.

Clearly, we would not expect the representation of the thought processes of someone who does not have a communicative intention to capture the sort of steps a communicator might take in order to satisfy a hearer's expectations of optimal relevance. Hence the incoherence of thought representations such as the one in (37):

(37) Yet in the Earthly Paradise, what had he done? He had made few friends. He had acquired a Mexican mistress with whom he quarrelled, numerous beautiful Mayan idols he would be unable to take out of the country, and he had - M. Laruelle wondered if it was going to rain.

(Malcolm Lowry, Under the Volcano, p. I6)

[Io] See the discussion of the opening section of Mansfield's 'At the Bay' in Fludernik (1993: 387-391). 
However, while we might not expect optimal relevance from M. Laruelle, we do expect optimal relevance from the author who is representing this thought. Lowry may not be communicating in the sense that he is TELLING us what M. Laruelle was thinking: he is simply showing us M. Laruelle's thoughts. However, as Sperber \& Wilson (I995: 52-53) have argued, even where an act of showing provides strong direct evidence for the basic layer of information (as in the case of opening a cupboard to let someone see the contents), there is an intention to draw some attention to the fact that the act was intentional and hence that the audience can assume that by paying attention they will discover relevant information. Thus the author must be assumed to communicate a guarantee that the effort invested by the reader in processing his text will be rewarded.

However, as Banfield has said, the author cannot be said to be speaking in fiction in the sense that he is communicating his thoughts. ${ }^{11}$ Putting it in her terms, the author does not 'speak' in the text, but rather 'creates a fictional world ... out of language, whether or not the language is attributed to a narrator' (Banfield 2005: 397). In texts with a narrator, the author can be said to represent or show us the thoughts of a narrator who is communicating with a narratee. In free indirect style texts, where there is no narrator, the author can be said to represent or show us the thoughts of a character who is either engaged in a fictional act of communication with another character (free indirect speech) or simply engaged in private thought. It is the latter sort of case which is the focus of this paper.

However, whether the reader is interpreting a text with a narrator or not, the reward for the effort he invests cannot lie in the improvement to the mutual cognitive environment of author and reader, since the author is showing us or representing the thoughts/utterances of another rather than communicating his own thoughts. Instead the reward lies in the relationship which is created between the reader and the fictional individuals in the fictional world which the author is representing. And this is more like the relationship that one might have with an individual whose life one is watching on film - except, of course, that in the sort of case under discussion in this paper, one has the impression of watching a film of an individual's private mental life. As Dillon \& Kirchhoff (I976: 438) say, 'FIS [free indirect style] is more often a strategy through which the narrator appears to withdraw from the scene and thus present the illusion of a character acting out his mental state in an immediate relationship with the reader'.

While the author may not have a 'voice' in the text, he is nevertheless responsible for deciding what is shown to the reader and when it is shown.

[II] The exception is, of course, in cases of so-called authorial intrusion. However, as Banfield (2005) points out, the fact that a text has authorial intrusions does not necessarily mean that all of its sentences are attributable to an author-narrator. See below for Dillon \& Kirchhoff's (1976) discussion of an example from Conrad's The Secret Agent. 
This means that the relationship just described is orchestrated by the author so that while readers are sometimes encouraged to adopt an empathetic attitude to the characters whose thoughts are being represented, in other cases they are encouraged to adopt a negative attitude towards them. This is achieved in a variety of ways. In some cases, the author simply lets a character reveal his own defects. For example, in 'Mr Reginald Peacock's Day', Mansfield's representation of Mr Peacock will lead most readers to the conclusion that he is an extremely vain man, so that his claim that he cannot stand vain men makes him seem all the more ridiculous. In other cases, an author may create a feeling of dissociation from one character by encouraging us to see him through the eyes of another. Thus in 'Prelude', Mansfield has us see Stanley Burnell do his exercises through the eyes of his wife Linda (see Blakemore 2008 for further discussion). And as Dillon \& Kirchoff (I976) show, an author may interrupt the representation of the thoughts of another with an utterance which represents his own view (authorial intrusion). Thus they argue that in the following extract from Conrad's Secret Agent, the utterance introduced by the sentence adverbial as a matter of fact indicates a view which contrasts with that of the character whose thoughts are being represented in the preceding segment: Mrs Verloc, who has just killed her husband, is panicking and hysterical, while the narrator is cool and detached:

(38) She looked up mechanically at the clock. She thought it must have stopped. She could not believe that only two minutes had passed since she had looked at it last. Of course not. It had been stopped all the time. As a matter of fact, only three minutes had elapsed from the moment she had drawn the first deep, easy breath after the blow, to this moment when Mrs Verloc formed the resolution to drown herself in the Thames.

(Joseph Conrad, The Secret Agent, p. 238)

More generally, the representation of a character's thought(s) must be interpreted in the context of the whole text, which, as Ehrlich (1990) as emphasized, may represent the perspectives of a range of different characters. Thus the conclusions we derive from the representation of a given character's thoughts may be affected by the interpretation of the representations of the thoughts of another, or, indeed, by the thoughts revealed by the sort of authorial intrusion discussed by Dillon \& Kirchoff.

\section{FIT AND PROCEDURAL MEANING}

In section 4, I have argued that what Banfield calls representation can be distinguished from an act of communication performed by a speaker who wishes to communicate his own thoughts. The latter communicates a guarantee of the relevance of an interpretation which the hearer assumes is 
an interpretation of the speaker's thoughts. The act of representation communicates a guarantee of the relevance of an interpretation which the reader will take to be an interpretation of the thoughts of someone other than the speaker - an individual whose identity must be established on the basis of pragmatic inference. This interpretation is unmediated by the thoughts of the speaker/writer responsible for producing the representation. In this section, I will show how this distinction allows us to account for the use of expressions which, according to relevance theory, do not occur as constituents of thoughts, in the representations of the thoughts of non-communicating subjects.

\section{I Discourse markers in FIT}

As we have seen, according to relevance theoretic accounts, discourse markers such as well in (39) (extracted from (I) above) and in (40), and after all in (4I) are inherently communicative or audience directed:

(39) And what made it doubly hard to bear was, she did not love her children. ... Even if she had the strength she would never had nursed and played with the little girls. No, it was a though a cold breath had chilled her through and through on each of those awful journeys; she had no warmth left to give them. As to the boy - well, thank heaven, mother had taken him.

(Katherine Mansfield, 'At the Bay', Collected Stories, p. 223)

(40) He said what he usually said, 'A shark got it'. Said it loud and it shut her up.... Well the other thing was, that after they'd told you about their diseases, their depressions and their stuffed relationships - after they'd come to an end of talking about themselves, they'd always want to know. Payback time.

(Patricia Grace, Dogside Story, p. 49)

(4I) He left the lawyer's office and drove through a city that was preparing to make its mark on the new millennium. Couldn't be bothered with it. Aslo couldn't be bothered with lawyers, family conferences or any of that ... Amira and Babs would give up once they understood they had no one on their side. They'd have to, especially once they knew about the birth certificate ... After all, they didn't really want Kid. It wasn't as though they showed any love for her.

(Patricia Grace, Dogside Story, p. 204)

Thus according to my account (Blakemore 2002), the key to the analysis of well lies in the communicative Principle of Relevance itself: 'In contrast with Jucker's (1993) relevance theoretic account which argues that well encodes deviation from optimal relevance and hence is an instruction to renegotiate the context, this account will propose that the information it encodes amounts to a green light for going ahead with the inferential processes 
involved in the recovery of cognitive effects, and the renegotiation of the context may be, but is not always, a consequence of interpreting the utterance in accordance with the constraint which well encodes' (Blakemore 2002: I38; emphasis in the original). If this analysis is right, the use of well is justified by the speaker's assumption that the audience needs such a green light, or, more generally, his aim of directing the audience to the intended interpretation for a minimum cost in effort. However, in (39) and (40), well is being used in the representation of a thought which must be attributed to a character who is not engaged in any form of communicative act.

Similarly, according to my analysis (Blakemore 1987,2002 ), the use of after all indicates that the relevance of the utterance it introduces lies in the contribution it makes to strengthening an accessible assumption. Thus the speaker of (42) intends that the hearer will take the proposition in (43a) together with the proposition in $(44 \mathrm{~b})$ and derive the proposition in $(44 \mathrm{c})$ :

(42) Ben can open Tom's safe. After all, he knows the combination.

(43) (a) Ben knows the combination for Tom's safe.

(b) If Ben knows the combination for Tom's safe, he will be able to open it.

(c) Ben can open Tom's safe.

(from Blakemore 2002: 89-90)

The effect of this inference is that the proposition expressed by the first segment of (42) is held with a degree of strength that is higher than it would have been prior to the interpretation of the second segment. In other words, according to this analysis, after all does not encode a constituent of the proposition expressed by the utterance that contains it, but rather encodes information about the inferential process which the hearer should use in deriving its the intended interpretation. In this way, it contributes towards the optimization of relevance by allowing the speaker to direct the hearer to the intended interpretation for a minimum cost in effort.

However, as it is used in (4I), after all does not introduce an utterance made by a speaker who is aiming for optimal relevance. There is no speaker as such - the utterance is simply a representation of the author's character's thoughts which is unmediated by the point of view of the communicating author. The question, then, is what role is after all playing if it is not directing an audience to an interpretation intended by a speaker?

As we have seen in section 4, the reward for processing FIT representations is an impression of having direct access to the thoughts of another. This is, of course an illusion: the reader only has access to these thoughts via the public representations which are provided by the author. Nevertheless the effect of free indirect style is an unmediated view not only of a character's thoughts but also of his thought processes. Thus the reader comes to know not only what a character thinks, but also how they came to have a thought and what role it plays in the development of new thoughts or in the 
modification of old ones. Similarly, it is not only transparent what a character decides, but also how they come to make that decision and how it affects other decisions. Now, a speaker or writer who describing what someone thinks can provide a conceptual representation of that person's thought processes. For example, I could report Linda's thought processes in the part of the story from which (39) is extracted thus:

(44) In this part of the story Linda is reflecting upon her lack of maternal instinct as she sits alone with her youngest child, a baby boy. She seems to be aware that most people would not be convinced by her revelation that she had no feeling for her children, particularly by her claim that she had no love for the baby, and becomes very defensive, demonstrating just how little she cares for him.

However, this is $m y$ interpretation of Linda's thought processes, and it does not leave you, the reader, any responsibility for deriving an interpretation of her mental state. In contrast, the use of well in the free indirect thought representation in (39), simply imposes a constraint on the relevance of the thought representation which contains it, and you are free to derive any interpretation of the thought which is consistent with that constraint. In particular, you are free to access whatever contextual assumptions you think would justify this use of well - that is, any contextual assumptions you think Linda would believe would justify this use of well. According to the analysis outlined above, these would have to derive from the need to demonstrate that the baby's presence does not detract from the plausibility of Linda's claims to any lack of maternal feeling, or, more generally, that the answer to the question 'what about the baby?' is indeed relevant. However, the point is that you have the responsibility to access these assumptions, and are left with the impression that you have accessed the same assumptions which are accessed by Linda as she has these thoughts. This contributes to the illusion that you are participating in her thought processes (in a way which you did not in (44)); and it means that you share in her subsequent unexpected change of heart and questioning of her own sincerity just a few lines down the page (I have abridged this passage for convenience here):

(45) The boy had turned over. ... And suddenly his face dimpled; it broke into a wide, toothless smile, a perfect beam, no less. ...

'Why do you keep on smiling?' she said severely. 'If you knew what I was thinking about, you wouldn't.'

But he only squeezed his eyes, slyly, and rolled his head on the pillow. He didn't believe a word she said. ...

Linda was so astonished at the confidence of this littlecreature ... Ah no, be sincere. That was not what she felt; it was something different; it was something so new, so ... The tears danced in her eyes [...].

(Katherine Mansfield, 'At the Bay', Collected Stories, p. 223) 
Similarly, a speaker/writer could provide (46) as an indirect representation of Rua's thought processes in the passage in (4I):

(46) In order to convince himself that he does not need the lawyers in order to persuade his community to accept that he was Kid's father, Rua tells himself that Amira and Babs would give up their claim because they did not really want or love her.

However, once again, this is my interpretation of Rua's thought processes, and, in contrast with (4I), it leaves you with no responsibility for recovering an interpretation of his mental state. Since after all simply imposes a constraint on the interpretation of the thought representation which it introduces, you are free to access the contextual assumptions which are needed in order to derive an interpretation which is consistent with the constraint it encodes. In particular, you will recall the incidents earlier in the book in which Kid has been maltreated by Amira and Babs, and consider whether anyone who treated a child in this way would fight for her custody. And you will assume that these are the thoughts which are going through Rua's mind - even though the author has not represented them in the text. In this way, you gain the impression that you are participating in his thought processes - an impression which is not derived from the indirect conceptual representation in (46).

The analysis of these two examples suggests that the use of discourse markers which encode procedures in free indirect thought representations lies in the fact that they allow the reader to take the responsibility for the recovery of assumptions which are not represented by the author in the text but which can nevertheless be attributed to the character whose thoughts are being represented. Since responsibility for the recovery of these assumptions is given to the reader, and the interpretation of the character's thoughts is unmediated by the thoughts of the author who is representing them, s/he is given the impression that $\mathrm{s} / \mathrm{he}$ is witnessing the characters mental processes directly - an impression which cannot be derived from indirect thought representations in which characters' thoughts come already interpreted by a communicator.

\subsection{Expressive interjections and expletives in FIT}

As Wharton (2003a, b) shows, the term INTERJECTION has been used to cover a wide range of phenomena ranging from expressions such as God, Heavens, Jeepers, damn, which are clearly linguistic, to expressions such as ah, ouch, wow and boo, which are not clearly linguistic. Terminology is confusing. Quirk et al. (1985) call expressions such as God, Heavens, etc. expletives, but note that they are not necessarily used as swearwords. Fludernik (I993) reserves the term interjection for lexical constituents such as God, Heavens etc and includes expressions such as ouch, ah and boo in the category labelled 
'hesitations'. Although both types of expression fall within her general category of 'expressives' or 'subjectivity markers', neither falls within her subcategory of 'addressee-oriented and speaker-oriented expressions', which include such expressions as Sir and Ma'am.

Kaplan's (1999) paper on the semantics of use, and Wharton's (2003a, b) work on interjections would seem to suggest that Fludernik's subclassification of subjectivity markers misses a generalization - a generalization which, I shall show, enables us to explain why all of these expressions play such an important role in free indirect thought representations. As I have said in the introductory section of this paper, both Kaplan's approach to the analysis of expressives (which includes expressions such as damn, Ma'am and ouch) and Wharton's analysis of expressions such as ah and wow might at first sight seem inconsistent with the use of these expressions in thought representations, since they both seem to assume that they are used in acts of communication. ${ }^{12}$ In this section, I shall argue that Wharton's approach in which ALL of these expressions encode procedural information even though they are not all properly linguistic enables us to explain their use in free indirect thought representations in the same way I have suggested for discourse markers.

Wharton's (2003a, b) analysis of interjections such as $a h$ and oh assumes that they are natural rather than linguistic, and hence are more like an angry or pleased tone of voice or a surprised facial expression than a word such as well or after all. At the same time, he argues that along with facial expressions of surprise, and an angry or pleased tone of voice, these interjections contrast with natural signs such as dark clouds or footprints in that they have a coded element which has developed in response to the need to communicate information to others. While this coded element contrasts with the encoded meanings of well and after all, in that it is not an input to inferential processes which result in the recognition of intentions, it is nevertheless like the meanings of these words in that it is procedural rather than conceptual. Specifically, it activates the retrieval of a range of propositional attitude descriptions - a range which might be narrowed in actual use by the use of particular contextual information, and, in spoken face-to-face discourse, by the use of facial expressions and prosody.

While this analysis helps explain why interjections such as $a h$ and $o h$ are natural in the same way as gestures or facial expressions, it also explains what they have in common with more obviously linguistic expressions such as good heavens or bother. If Wharton is right, then none of these expressions encodes a constituent of a thought: they simply activate a range of

[12] The same point applies to Potts' (2007) analysis of expressive NP epithets and APs. This paper focuses on the use of expressions such as $a h$ and good heavens; however, I believe that the suggestions I make for the use of these expressions in free indirect thought representations can be applied to expressive NP epithets and APs. 
representations which are assumed to be meta-representations of the thoughts and emotions of the person who uses them. Moreover, as Wilson \& Wharton (2006) point out, this approach allows us to explain why the meanings of interjections, facial expressions, or the discourse markers discussed in section 4 are so elusive, so contextually shaded and so hard to pin down. ${ }^{13}$

This, of course, is the key to the role of these expressions in representations of thought. One of the main challenges for an author who is aiming to give the impression that a character is acting out his mental state in an immediate relationship with the reader is to produce utterances which enable the reader to identify ineffable aspects of thought - emotions which cannot be translated into a public language, attitudes which cannot be expressed directly. How, for example, is an author to give the reader the impression that $\mathrm{s} / \mathrm{he}$ has direct access to the Linda's thoughts in (45) (above) as she wrestles with the unfamiliar emotions of motherhood or the strange mixture of excitement and regret felt by Leila as she prepares for her first ball in (4) (repeated below)?

(4) Oh, how marvellous to have a brother! In her excitement Leila felt that if there had been time, if it hadn't been impossible, she couldn't have helped crying because she was an only child and no brother had ever said 'Twig?' to her; no sister would ever say, as Meg said to Jose at that moment, 'I've never known your hair go up more successfully than it has tonight'.

(Katherine Mansfield, 'Her First Ball', Collected Stories, p. 337)

What the author does, of course, is to produce an expression which encodes a procedure for activating a range of emotional attitudes. The rest is left to the reader. Thus the reader of (45) will draw on his experience of reading the earlier passage in the book (some of which is extracted in (39) above), and his own imagination to narrow down the range of emotions activated by Linda's $a h$ to construct his own particular representation of Linda's emotional struggle. Similarly, the reader of (4) is expected to draw on the earlier representations of Leila's thoughts as she prepares for the ball and his own imagination to narrow down the range of emotions activated by $o h$. In other words, the fact that these expressions cannot be paraphrased in fixed conceptual terms and interact with the context means that the reader has most of the responsibility for the interpretation of the thoughts represented, and this contributes to an impression of emotional immediacy which would not be recovered from a narrator's interpretation of those thoughts.

[13] For further discussion of the elusive nature of the meanings of discourse markers, see Blakemore (2002: 82-83). For discussion of the elusiveness of the meanings of expressive adjectives and NP epithets, see Potts (2007). 


\section{CONCLUSION}

In this paper I have argued that the insights of Banfield's (I982) 'nonarrator' approach to free indirect style can be accommodated in a relevance theoretic approach to the representation of thought in fiction. The result is an account in which the author's act of revealing a character's thoughts communicates a guarantee of optimal relevance - a guarantee which justifies the effort which the reader invests in deriving meta-representations of those thoughts from the evidence which the author provides. However, as we have seen, the reward for this effort is a meta-representation of a character's thoughts which is unmediated by the thoughts of the author who is responsible for producing the text. It as if having provided the evidence, the author then withdraws thus allowing the reader to construct his own interpretation of the character's thoughts on the basis of the Principle of Relevance and contextual assumptions derived from his own interpretation of the surrounding text and his imagination. The result is as Dillon \& Kirchhoff (I976) have described it, an illusion of a character acting out his mental state in an immediate relationship with the reader.

Within this framework, the use of discourse markers and interjections in free indirect thought representation contribute to this illusion by imposing constraints on interpretation which encourage the reader to draw on his own imagination either to create meta-representations of thoughts which are not represented in the text or to create meta-representations of otherwise ineffable emotions and thoughts. Because these expressions do not encode constituents of conceptual representations, but simply activate processes which result in conceptual representations, they are particularly effective for an author who wishes the reader to take responsibility for the interpretation process. As Sperber \& Wilson (I995) and Pilkington (2000) have shown, the more responsibility the reader/hearer is given for the interpretation process, the greater the sense of intimacy that is communicated between communicator and audience. The point about free indirect thought representations is, of course, that there is no communicator speaking in the text, and the intimacy that is created by handing the responsibility for interpretation to the reader is a relationship between reader and (fictional) character.

In this way, then, this paper has shown not just how the use of these audience-directed expressions is justified in free indirect thought representations, but also why they are so effective: their use contributes to the sense of LISTENING to characters speak their thoughts and grapple with their emotions - an experience which we cannot have in the real world.

\section{REFERENCES}

Bach, Kent. 1999. The myth of conventional implicature. Linguistics and Philosophy 22, 327-366. Banfield, Anne. 1982. Unspeakable sentences: Narration and representation in the language of fiction. London: Routledge \& Kegan Paul. 


\section{DIANE B LAKEMORE}

Banfield, Anne. 2005. 'No-narrator' theory. In David Herman, Manfred Jahn \& Marie-Laure Ryan (eds.), The Routledge encyclopaedia of Narrative Theory, 396-397. London: Routledge.

Blakemore, Diane. 1987. Semantic constraints on relevance. Oxford: Blackwell.

Blakemore, Diane. 2002. Relevance and linguistic meaning: The semantics and pragmatics of discourse markers. Cambridge: Cambridge University Press.

Blakemore, Diane. 2008. Apposition and affective communication. Language and Literature I7.I, $37-58$.

Blass, Regina. 1989. Grammaticalization of interpretive use: The case of 're' in Sissala. Lingua 79, 229-236.

Blass, Regina. 1990. Relevance relations in discourse: A study with special reference to Sissala. Cambridge: Cambridge University Press.

Bronzwaer, W. J. M. 1970. Tense in the novel. Groningen: Wolters-Noordhoff.

Carston, Robyn. 2002. Thoughts and utterances. Oxford: Blackwell.

Chatman, Seymour. 1978. Story and discourse: Narrative structure in fiction and film. Ithaca, NY: Cornell University Press.

Conrad, Joseph. 1963. The secret agent. Harmondsworth: Penguin Books. [First published 1907]

Dickens, Charles. I979. Our mutual friend. Harmondsworth: Penguin Books. [First published I860]

Dickens, Charles. 1978. Little Dorrit. Harmondsworth: Penguin Books. [First published I857]

Dillon, George \& Frederick Kirchhoff. 1976. On the form and function of free indirect style. PTL: A Journal for Descriptive Poetics and Theory of Literature I, 43I-440.

Ehrlich, Susan. 1990. Point of view: A linguistic analysis of literary style. London: Routledge.

Fludernik, Monika. 1993. The fictions of language and the languages of fiction. London: Routledge.

Grace, Patricia. 200I. Dogside story. Harmondsworth: Penguin Books.

Hall, Alison. 2007. Do discourse markers encode concepts or procedures? Lingua III.I, I49-I74.

Ifantidou-Trouki, Elly. 1993. Sentence adverbials and relevance. Lingua 90, 69-90.

Jucker, Andreas H. 1993. The discourse marker well: A relevance-theoretic account. Journal of Pragmatics 19, 435-452.

Kaplan, David. I997. What is meaning? Ms., University of California, Los Angeles.

Lowry, Malcolm. I962. Under the volcano. Harmondsworth: Penguin Books. [First published by Jonathan Cape, 1947$]$

Mansfield, Katherine. 198I. The collected short stories. Harmondsworth: Penguin Books.

Pilkington, Adrian. 2000. Poetic thoughts and poetic effects: A relevance theory perspective. Amsterdam: John Benjamins.

Potts, Christopher. 2005. The logic of conventional implicatures. Oxford: Oxford University Press.

Potts, Christopher. 2007. The expressive dimension. Theoretical Linguistics 33.2, I65-197.

Quirk, Randolph, Sidney Greenbaum, Geoffrey Leech \& Jan Svartvik. I985. A comprehensive grammar of the English language. London: Longman.

Reinhart, Tanya. I983. Points of view in language - the use of parentheticals. In Gisa Rauh (ed.), Essays on deixis, I69-194. Tübingen: Gunter Narr.

Rieber, Stephen. 1997. Conventional implicatures as tacit performatives. Linguistics and Philosophy 20, 5I-72.

Schlenker, Philippe. 2004. Context of thought and context of utterance: A note on free indirect discourse and the historical present. Mind \& Language I9. I, 279-304.

Sharvit, Yael. 2008. The puzzle of free indirect discourse. Linguistics and Philosophy 3I.3, 353-395.

Sperber, Dan \& Deirdre Wilson. 1995. Relevance: Communication and cognition (2nd edn.). Oxford: Blackwell. [First published 1986]

Sternberg, Meir. 1982. Point of view and indirections of direct speech. Language and Style I5.I, 67-II7.

Tannen, Deborah. 1989. Talking voices: Repetition, dialogue and imagery in conversational discourse (Studies in Interactional Sociolinguistics 6). Cambridge: Cambridge University Press.

Wharton, Tim. 2003a. Natural pragmatics and natural codes. Mind \& Language I8, 447-477.

Wharton, Tim. 2003b. Interjections, language and the 'showing-saying' continuum. Pragmatics \& Cognition II, 39-9I. 


\section{COMMUNICATION AND THE REPRESENTATION OF THOUGHT}

Wilson, Deirdre. 2000. Metarepresentation in linguistic communication. In Dan Sperber (ed.), Metarepresentation: A multi-disciplinary perspective, 4II-448. Oxford: Oxford University Press.

Wilson, Deirdre. 2006. The pragmatics of irony: Echo or pretence. Lingua II6, I722-I743.

Wilson, Deirdre \& Dan Sperber. 1993. Linguistic form and relevance. Lingua 90.I/2, I-25.

Wilson, Deirdre \& Tim Wharton. 2006. Relevance and prosody. Journal of Pragmatics 38, I559-I579.

Woolf, Virginia. I964. To the lighthouse. Harmondsworth: Penguin Books. [First published by the Hogarth Press, 1925]

Author's address: School of Languages, University of Salford, Salford,

Greater Manchester M5 4WT, UK

D.Blakemore@salford.ac.uk 